\title{
Preparation, characterization and application of fluorinated acrylate copolymer emulsion for the conservation of stone building heritages in Putuo Zongcheng Temple, China
}

\section{Jiangfang Chang}

Shijiazhuang Tiedao University

Qinghe Niu ( $\square$ qinghniu@163.com )

Shijiazhuang Tiedao University https://orcid.org/0000-0001-5695-8355

\section{Wei Wang}

Shijiazhuang Tiedao University

\section{Research article}

Keywords: fluorinated acrylate copolymer, stone building heritage conservation, contact angle, ultraviolet aging test, weathering, Putuo Zongcheng Temple

Posted Date: December 22nd, 2020

DOl: https://doi.org/10.21203/rs.3.rs-131729/v1

License: (c) (1) This work is licensed under a Creative Commons Attribution 4.0 International License.

Read Full License 


\section{Abstract}

Recently, the stone building heritages in Putuo Zongcheng Temple are experiencing a certain degree of weathering damage, which mainly manifests in the blistering, fissuring, flaking and detachment of the carved balustrades of stone bridge, the footings of wall, the front paws and pedestals of stone lions. To prevent the deterioration of the stone building heritages, the fluorinated acrylate copolymer emulsion was successfully prepared with ethyl metrhacrylate, n-butyl acrylate and 2,2,3,4,4,4-hexafluorobutyl methacrylate as monomers. The structure and surface morphology characteristics of this copolymer were described the Fourier Transform infrared spectroscopy (FTIR) and scanning electron microscope (SEM), respectively. The FTIR spectra confirms that the adopted monomers have been involved in during the copolymer polymerization process. The SEM images reveal that the surface of the prepared copolymer is obviously more dense, compact and smooth than the porous structure of stone building heritages. The ageing resistance of the copolymer was quantitatively studied by the ultraviolet aging test, the contact angle and imbibition spontaneous tests were adopted to estimate the wettability alteration of the copolymer emulsion for the stone samples. Results show that the mass loss rate of the prepared copolymer increases rapidly and then tends to be stable when irradiated by ultraviolet light. And the fluorinated copolymer with $16.65 \%$ HFMA content possesses the optimal ageing resistance and the superb hydrophobicity. The contact angles of the coated stone samples range from $91.90^{\circ}$ to $119.80^{\circ}$, which are all larger than $18.80^{\circ}-69.05^{\circ}$ of the un-coated samples. Similarly, the spontaneous imbibition test also ensures that, both the maximum water absorption capacity and the imbibition equilibrium time of the samples treated by this copolymer emulsion are lesser. Considering the influence of water on rock weathering, the fluorinated copolymer emulsion coating is an potential method to avoid the degrading of stone building heritages, because it depresses the infiltration of water and then avoids or weakens the dissolution effect, salt crystallization, water absorption swelling and freeze-thaw weathering.

\section{Introduction}

Carbonate-based rocks are always the indispensable materials for the stone building heritages, e.g., the mural paintings of the underground three-chambers tombs were drew on carbonate substrates[1]; the builings of the Roman City of Dougga (Tunisia) were constructed by the Eocene nummulitic carbonate rock[2]; the Kylin carved-stone in Kylin countryside (Nanjing, China) was also made from the carbonate rock. After a long historical period, the stone buildings could be deteriorated when water penetrates into them, due to the carbonate dissolution, freezing/thawing cycles or crystallization/precipitation, and biological degradation[3-7].

In recent years, different kinds of synthetic copolymers have been widely employed on stone buildings as adhesives, consolidants and surface protectives of cultural heritages[8-11]. Acrylic resins were usually be used for protecting the stone building by coating on it. This is because that acrylic resins possess the characteristics of superior hydrophobicity and adhesion to the surface of porous matirals[12]. However, in outdoor environments, acrylic resins are easily to be photodegraded due to the presence of the methyl group in a-position and the nature of the alcoxy group in the ester[13, 14]. Alkoxysilanes are another class 
of materials employed as stone protective[15], basing on that the reations of alkoxysilanes lead to the formation of network on the surface of stone buildings. Specially, the alkoxysilanes are hydrolyzed by water to produce alkoxysilanols[16], which then condense to form a polysiloxane polymer with the elimination of water or alcohol[17]. Unfortunately, the alkoxysilanes are unable to repel oil[18]. This shortcoming is unacceptable for high-porosity stone as a decoration or monument, because contaminations of stone building heritages will lower or lose its historical, cultural and ornamental values.

Fluorinated copolymers are the excellent nonwettable and weather-resistant coatings[19]. Scholars have confirmed that the fluorine atoms undertake the paramount role of lowering the surface free energy, and the reduction extent can be related to the chemical composition in the sequence $-\mathrm{CF}_{3}>-\mathrm{CF}_{2}->-\mathrm{CH}_{3}>$ $-\mathrm{CH}_{2}-[20]$. Therefore, introducing fluorine atoms onto the long perfluoroalkyl side chains can reduce the low surface free energy to the greatest extent and hence enhance the hydrophobicity of surfaces[21, 22]. And the synthetic fluorinated polymers have been used to restrain the deterioration of stone materials $[9$, 23-25]. Besides the wettability, weatherability is another factor influencing the performance of fluorinated copolymer, because the coating could accelerate the degradation effect and reduce its service life when exposed to harsh outdoor conditions[26]. In fact, ultraviolet radiation can increase the ratio of $C$ $=\mathrm{O}$ to $\mathrm{C}-\mathrm{H}$ band areas but decrease the concentration of $\mathrm{C}-\mathrm{F}$ group of fluorinated copolymer due to the photo-oxidation effect[27], which will induce the lose of the protection effect for stone building heritages. Additionally, both the wettability and weatherability of a fluorinated copolymer are raleted to the fluorine content[28, 29], hence choosing a appropriate fluorine ratio is essential to compound a high-performance fluorinated copolymer.

The focus of this paper is on preparing a kind of available fluorinated acrylate copolymer emulsion, then investigating its weatherability and hydrophobicity, and finally clarifying its application for the conservation of stone building heritages. A series of ethyl metrhacrylate, n-butyl acrylate and 2,2,3,4,4,4hexafluorobutyl methacrylate were adopted to synthesuize the fluorinated acrylate copolymer emulsion. The structure of the fluorinated copolymer will be characterized by the fourier transform infrared spectroscopy (FTIR), the surface morphologies will be examined using scanning electron microscope (SEM), the wettability of the fluoropolymer will be measured by contact angle test and the wettability alteration effect of stone building heritages in Putuo Zongcheng Temple will be evaluated by the spontaneous imbibition test.

\section{Description Of The Case Study And Historical Background}

Putuo Zongcheng Temple is located at the north of Chengde City, Hebei Province, China and belonged to a part of the Mountain Resort and its Outlying Temples (see Fig. 1). Historically, it was built between 1776 and 1771, aiming to celebrate the birthday of the Qianlong Emperor. The Putuo Zongcheng Temple was originally dedicated to the Qianlong Emperor to celebrate his birthday, as well as provide Hebei with a temple of equal size and splendor as the Potala Palace in Lhasa. The whole temple covers an area of $220,000 \mathrm{~m}^{2}$, taking the gate, the Stele Pavilion, the Five Pagodas Gate, and more than 30 flat-top 
blockhouse-style white terraces as its main buildings. With a fusion of Chinese and Tibetan architectural style, Putuo Zongcheng Temple has extreme high artistic value, and it was selected into the world immaterial heritages by the United Nations Educational, Scientific and Cultural Organization (UNESCO) in 1994.

Most bases of the houses in this temple is made of stone materials (Fig. 2b), additionally, the bridges and stone cultural relics (monument, stone lion and stone elephant, etc.) are carved from local carbonate rocks (Fig. 2a and Fig. 2c). Recent years, the stone building heritages in Putuo Zongcheng Temple have been experiencing a certain degree of weathering damage. The carved balustrades of the stone bridge has been fissured and exfoliated, resulting from the vandalism and weathering; the footing of wall has been corroded due to the long-term soaking by rainwater; weathering damage can also be found from the stone lions, the front paws and pedestals exhibit substantial local destroy after rainwater erosion and solar radiation (see Fig. 3). Obviously, rainwater erosion is the main inducer of this hazard, after cognizing which, the cultural relic protection staff have adopted some remedial measures: (1) place a guardrail around the damaging stone cultural relics, and (2) cover several plastic films over the body of stone cultural relics (see Fig. 2d). Apparently, these measures are temporary and can not completely eradicate this weathering damage.

\section{Experimental}

\subsection{Materials}

Ethyl metrhacrylate (EMA) was purchased from Changzhou Guxu Chemical Co. Ltd., China. Ethanol and n-butyl acrylate (BA) were purchased from Nanjing Chemical Reagent Co. Ltd., China. 2,2,3,4,4,4hexafluorobutyl methacrylate (HFMA) was available from Shanghai Hongshun Biotechnology Co. Ltd., China. N,N'-methylenebisacrylamide (MBAA) purchased from Hubei Jusheng Technology Co. Ltd., China was used as the crosslinker. 2,2'-azoisobutyronitrile (AIBN) purchased from Ji'nan Jieao Chemical Reagent Co. Ltd., China was served as the initiator. The rock cores (about $5 \mathrm{~cm}$ long and $2.5 \mathrm{~cm}$ in diameter) were prepared from the weathered and exfoliated rock blocks in Putuo Zongcheng Temple.

\subsection{Emulsion copolymerization}

The fluorinated acrylate copolyme emulsion in this paper was prepared basing on the following procedures: (1) the monomers mixture of EMA and BA with the mass ratio of 7:3 was fist added to a clean and dry test tube. Then the monomers mixture was respectively mixed by HFMA, crosslinker MBAA and initiator AIBN, the mass percents of MBAA and AIBN are $8 \%$ and $2 \%$, the mass percents of HFMA is changed in $0,9.08 \%, 16.65 \%, 23.05 \%, 28.54 \%$ and $33.30 \%$. Finally, they were dissolved by ethanol with the mass of 1.5 times to monomers mixture and homogenized by a magnetic stirrer in this test tube. (2) The reactor was purged with nitrogen before the reaction is started. The prepared sample was added into the reactor and heated through a water bath at $30^{\circ} \mathrm{C}$ and kept for $30 \mathrm{~min}$. Then the water bath temperature was elevated to $50{ }^{\circ} \mathrm{C}$ to promote the dissolution of the crosslinker and initiator, after the disappearance 
of the coagulum, the temperature was adjusted to $60^{\circ} \mathrm{C}$ and maintained about $10 \mathrm{~min}$, last, it was constantly increased to $68-70^{\circ} \mathrm{C}$ to impel the polymerization reaction until the stable latex was formed.

\subsection{Measurements}

\subsubsection{Structure characterization}

Fourier Transform infrared spectroscopy (FTIR) can be used to detect the polymer structure by an incident infrared light with continuous wavelength. In this paper, the test instrument NEXUS 870 (Nicolet Instrument Co. USA) was adopted to obtained the FTIR spectra of fluorinated acrylate copolymer by the thin film method. The wanvenumber ranges from $400 \mathrm{~cm}^{-1}$ to $4700 \mathrm{~cm}^{-1}$, with a resolution of $0.125 \mathrm{~cm}^{-}$ 1 .

\subsubsection{Morphology}

To observe the surface topography, the field emission scanning electron microscope (FESEM) (MiRa3, TESCAN, Czech Republic) was employed. Latex was suppressed onto glass slides and dried in the thermostat at $60^{\circ} \mathrm{C}$ for $2 \mathrm{~h}$. After cooling down, the copolymer samples were sprayed with gold before observation[30].

\subsubsection{Weather-resistance test}

To detect the weatherability of the prepared fluorinated copolymer emulsion, an UV-aging test box (QPanel, USA) was employed and corresponding experimental procedures were refered to the Chinese National Standard GB/T 14522 - 2008. The wavelength and the power of the UV lamp in the test box were $340 \mathrm{~nm}$ and $0.77 \mathrm{~W} / \mathrm{m}^{2}$, respectively. During the test process, the ambient temperature in the chamber was constantly kept at $40{ }^{\circ} \mathrm{C}$. The samples were removed from the UV-aging test box to test the mass loss rate by a high-precison balabce every day.

\subsubsection{Wettability characterization}

Contact angle defined as the included angle of solid-liquid boundary line is a parameter to decrible the moist degree. A video-based optical contact angle measuring system OCA15Pro (Dataphysics Instrument $\mathrm{GmbH}$, Germany) was used to measure the wettability of water to rock/copolymer film surface. About a volume of $6 \mu \mathrm{L}$ deionized water was used to form a drop, and then a camera was employed to record the side view images. The surface of the samples were cleaned by tissue paper at each experimental interval The whole process was conducted as soon as possible and the experimental temperature was room temperature.

To further detect the wettability changes of stone sample before and after the flourinated copolymer coating, the spontaneous imbibition test was performed by a self-designed device (see Fig. 4). The seclected samples (about $5 \mathrm{~cm}$ long and $2.5 \mathrm{~cm}$ in diameter) were hung vertically and placed onto the surface of water, and a balance was used to monitor the changes of weight and recorded in the computer. When the sample was contacted with water, the water will imbibe into its inner structure. The real-time weight varieties will be exhibited in the computer and plotted as the function of time, and then the rate of 
imbibition spontaneous was calculated to evaluate the wettability alteration of flourinated copolymer for the stone samples from Putuo Zongcheng Temple.

\section{Results And Discussion}

\subsection{Structure of the copolymer}

HFMA is attractive in the synthesis and modification of high-performance coatings because of its high thermal stability, exceptional weathering resistance and low moisture absorption[31]. Therefore, the structures of copolymer with and without additing HFMA were tested by FTIR (Fig. 5). At 1500-1700 $\mathrm{cm}^{-}$ ${ }^{1}$, the characteristic absorption $\mathrm{C}=\mathrm{C}$ bond is weaken or disspared, showing that the monomers were polymerized due to the copolymerization in the emulsion copolymerization process, especially for the $\mathrm{C}=$ $C$ bond at the characteristic peak of $1676.03 \mathrm{~cm}^{-1}$. And comparing to the copolymer without HFMA, copolymer containing HFMA exhibits more obvious characteristic absorption peaks at $3367.49 \mathrm{~cm}^{-1}\left(\mathrm{O}^{-}\right.$ $\mathrm{H}$ bending stretching), $2981.34 \mathrm{~cm}^{-1}\left(-\mathrm{CH}_{3}-\right.$ stretching vibration), $754.12 \mathrm{~cm}^{-1}\left(-\mathrm{CH}_{2}-\right.$ stretching vibration in long chain alkane) and $1735.83 \mathrm{~cm}^{-1}$ ( $\mathrm{C}=0$ symmetric stretching). Additionally, the other difference is that C-F bonds are clearly observed at the peaks at $1240.15,1172.64$ and $1027.99 \mathrm{~cm}^{-1}$. This indicates that the fluorine-containing monomer has been introduced into this copolymer and it was successfully prepared.

\subsection{Ageing resistance}

The stability (ageing resistance) is an index that we must take into account to evaluate the application value of the prepared copolymer. The energy possessed by the ultraviolet light reaching the ground can disrupt the internal chemical chains of polymer structures[32], and this photoinduced chemical degradation will aggravate accompanying by the oxidation reaction[33]. During the ultraviolet radiation process, the average molecular weight of the copolymer will be reduced because of the radiation degradation[34]. Therefore, the mass loss rate $\left(M_{\perp}\right)$ was used to characterize the ageing process during the UV-aging test, which was defined as:

$$
M_{L}=\left(m_{0}-m_{1}\right) / m_{0} \times 100 \%
$$

Where $m_{0}$ is the mass of the prepared copolymer before conducting the UV-aging test; $m_{1}$ is the mass of the prepared copolymer after ultraviolet radiation in one cycle.

To find out the optimum ratio, the prepared copolymers with adding different HFMA contents $(0,9.08 \%$, $16.65 \%, 23.05 \%, 28.54 \%$ and $33.30 \%$ ) were adopted to conduct the UV-aging test, which runs for one month and the mass of the prepared copolymer was monitored every day. The mass loss rates were shown in Fig. 6 . The mass of the six copolymers all decrease with the increase of the ultraviolet radiation time. The mass loss rates exhibit two obvious stages, the first one is the rapid growth stage and the 
second one is the stationary stage. For the copolymers with $0 \%$ and $16.65 \%$ HFMA content, the turning point is at about 10 days; for the copolymers with $9.08 \%$ and $23.05 \%$ HFMA content, the turning point is at about 15 days; and for the copolymers with $28.54 \%$ and $33.30 \%$ HFMA content, the turning point is at about 20 days. Additionally, Fig. 7 indicates that the maximum mass loss rate is not completely proportional to the additive amount of HFMA. Specially, the copolymer with $16.65 \%$ HFMA content possesses the minimum mass loss rate, which enlightens us that adding moderate HFMA will help to the ageing resistance of prepared copolymer, or at least that the synthetic copolymer will not be fast aging and lost its utility value.

\subsection{Contact angle of the copolymer}

To investigate the water repellency of the prepared copolymer when applied to the conservation of stone building heritages, the contact angle test of the copolymer film were conducted. Previous scholars have confirmed that $-\mathrm{CF}_{3}$ group is capable of enhancing the hydrophobicity of a copolymer film surface[28, 35-37]. This is because the polar $\mathrm{OH}$ - groups of the stone surface are replaced by the non-polar and thermally stable $-\mathrm{CF}_{3}$ groups originating from the fluorinated copolymer[38], impelling the formation of a hydrophobic surface on the stone building heritage[36].

However, ascertaining the proper HFMA proportion to maximize the hydrophobicity of the obtained copolymer is needed. And Fig. 8 exhibits the changes of contact angle with the increasing HFMA contents. As a whole, the contact angle increases with the increase of HFMA content, which confirms the consensus that the fluorinated monomer can modify the wettability of the prepared copolymers. This is due to that the fluorine atoms migrate freely to the surface of the film during its curing process, decreasing the surface free energy and advancing the hydrophobicity[38]. Nevertheless, the surface hydrophobicity could not be further improved or even be weakened when increasing HFMA content after $16.65 \%$, this phenomenon reveals that the fluorine atoms have been saturated and the hydrophobicity could not be further improved by adding more HFMA. Additionally, the adhesion between the fluorinated copolymer and stone surface is negatively related to the hydrophobicity. The adhesion will be reduced by increasing HFMA content after the fluorine atoms are saturated on the stone surface, hereat, the rainwater will penetrate into the stone through the space between the stone surface and the fluorinated copolymer film. This circumstance avianizes the hydrophobic performance of the stone building heritage coating by fluorinated copolymer.

\subsection{Surface characteristics}

The surface morphology of the stone samples and prepared copolymer were investigated by using SEM analysis (Fig. 6). After experiencing a long-term weathering, the surface structure of the stone building heritage has been changed. Apparently, as shown in Fig. $6 \mathrm{a}$ and Fig. $6 \mathrm{~b}$, the surface of weathered stone samples becomes more loose and rough, resulting in the generating of massive secondary pores. These pores are belonged to macropores[39, 40], which provide pathways for water flow or infiltration and solute transport[41]. On the one hand, the increased porosity will cause the weathered stones to be weakened 
and lose their strength directly[42], and on the other hand, it will aggravates this damage by driving the reaction of minerals with rainwater penetrating through the secondary pore structure.

Figure $9 \mathrm{c}$ and Fig. $9 \mathrm{~d}$ unfold the surface structure of the prepared copolymer, they are obviously more dense, compact and smooth than that of weathered stone samples. However, comparing to Fig. $9 \mathrm{~d}$, some fissures are developed on the surface of copolymer film exhibited in Fig. 9c, indicating that HFMA is beneficial to the formation of the copolymerization emulsion in this paper. And HFMA changes the surface structure of the prepared copolymer and makes it more smooth and firm, which may be come down to two reasons: (1) the fluorocarbon groups with a low surface energy are arranged to dense networks on the coating surface; (2) fluorinated groups increase the stiffness of coating surface and lower the possibility of cracking.

\subsection{Wettability alteration of the stone building heritage surface by coating fluorinated copolymer} Exposing to natural environments (illumination, rainfall and temperature cyclic changes, etc.) for a long time, historical stone buildings will be relaxedly weared out, especially for which without any effective conservation measures. As stated by previous scholars[43, 44], water, either alone or in combination with other environmental elements, will increase the damage of the stones existing in the atmosphere. Therefore, cutting off the contact of water and stone is requisite to reduce the progressive deterioration of the stone building heritages.

Section 4.4 has certified the copolymer with $16.65 \%$ HFMA content possesses the strongest hydrophobic features. As suggested by Licchelli et al. that the contact angle measurement is related to an "instant" water repellence behaviour, while the long-term water resistance can be better assessed by evaluating the water absorbed through the treated stone surface during the capillary absorption test[45]. Therefore, to ascertain the wettability modifications of the un-coated and coated stone samples by this kind of fluorinated a copolymer, both the contact angle and spontaneous imbibition tests of copolymer film were performed.

To guarantee the repeatability of results, the contact angle tests were conducted at least three times for each stone sample. The contact angles and test errors of the stone samples before and after fluorinated acrylate copolymer emulsion coating were shown in Fig. 10. The contact angles of the stone samples before coating fall in the range of $18.80^{\circ}-69.05^{\circ}$, contrarily, those of the stone samples after coating vary from $91.90^{\circ}-119.80^{\circ}$. Apparently, the contact angles of the stone surface are greatly increased by $58.35 \%-428.95 \%$ via coating the fluorinated acrylate copolymer emulsion. This shows that the fluorinated monomer can strongly improve the hydrophobicity of stone surface, as reported by other researhers[4649].

Assuming the water imbibes in a piston-like manner and the pressure gradient in the gas phase ahead of the water front can be neglected, the relationship of imbibition water volume with the time can be described as[50]: 


$$
\frac{V_{i m b}}{A_{c}}=\sqrt{\frac{2 p_{c} \phi k_{w} S_{w}}{\mu_{w}} t}
$$

Where $A_{c}$ is the cross-sectional area of sample; $P_{c}$ is the capillary pressure; $k_{w}$ is the permeability of water; $\varphi$ is the porosity; $S_{w}$ is the aqueous phase saturation; $\mu_{w}$ the wetting-phase viscosity; $t$ is the imbibition time; $A$ is the imbibition coefficient, $A=\sqrt{\frac{2 p_{c} \phi k_{w} S_{w}}{\mu_{w}}}$. For the spontaneous imbibition test, the water imbibition volume was monitored every three minutes until it reaches the stable value. The relationship of water imbibition volume with imbibition time was shown in Fig. 11. The imbibition rate is the slope of $V_{i m b} / A_{c}$ and $\sqrt{t}$ and has been exhibited in Fig. 12.

Where $A_{C}$ is the cross-sectional area of sample; $P_{c}$ is the capillary pressure; $k_{w}$ is the permeability of water; $\varphi$ is the porosity; $S_{W}$ is the aqueous phase saturation; $\mu_{W}$ the wetting-phase viscosity; $t$ is the imbibition time; $A$ is the imbibition coefficient, . For the spontaneous imbibition test, the water imbibition volume was monitored every three minutes until it reaches the stable value. The relationship of water imbibition volume with imbibition time was shown in Fig. 11. The imbibition rate is the slope of and and has been exhibited in Fig. 12.

It can be seen that the stone adsorbing water unfolds prominent periodic features, i.e., the imbibition volume of water gradually increases first and then stabilizes at its equilibrium value. For a material with a certain level of wettability (e.g., carbonate rocks), its pore walls will produce an adhesive force for water becaue of the molecular interactions when stones are in contact with water, which drives water penetrate to its internal space. The gravity of water increases with the increase of water quantity infiltrated into stone, and the imbibition effect will be ceased until the adhesive force is equal to the gravity of wateruptake. Additionally, stone sample coated by fluorinated copolymer can reduce its maximum water absorption capacity, specially, the maximum water absorption capacity of the treated sample is only $26.9 \%$ than that before being treated. The imbibition rate can be divided into rapid imbibition, slow imbibition and imbibition equilibrium stages. The rapid imbibition and slow imbibition stages of stone sample after treating all get shorter and imbibition equilibrium stage is reached earlier, comparing before treating. This reconfirms the wettability alteration of fluorinated copolymer to stone building heritages in Putuo Zongcheng Temple.

\subsection{Mechanisms for stone building heritage conservation by copolymer coating}


Considering the influence of water, the deterioration of stone building heritage can be attributed to three reasons: (1) dissolution effect, (2) salt crystallization and water absorption swelling and (3) freeze-thaw weathering.

The stone building heritage in this work is mainly consisted by carbonate minerals, e.g., calcite and dolomite, as shown in Fig. 13. The carbonate minerals account for $84.10 \%-91.63 \%$ of all the minerals in the seclected samples. With rapid urbanization and development of transport infrastructure, the urban air quality of China has been seriously polluted with high concentrations of sulfur dioxide. As reported by Wang et al.[51], the $\mathrm{pH}$ of the precipitations in Chengde is lower than 5.6 due to the emission of $\mathrm{SO}_{2}$ and $\mathrm{NO}_{\mathrm{x}}$. The acid rain is easily to dissolve the carbonated minerals in stone buildings. This can change the pore structure, specially, during the acid immersion test, the porosity connectivity increases and pores extend inward due to the dissolution by acid rain $[52,53]$. The altered pore structure will absorb more water and further changes the microstructure, inducing the degradation of stone building heritage.

Additionally, the seasonal precipitation distribution is also extremely uneven in Chengde region, the maximum average monthly precipitation air humidity was appeared in July, while the minimum value was in January, and the former is 97.43 times larger than the latter (see Fig. 14). The uneven distributed precipitation periodically changes the atmospheric humidity, and inducing the drying-wetting alternation effect $[54,55]$. During rainy season, the soluble salts originating from the carbonate rock dissolution and rainwater carrying are transported to the surface of stone buildings, while during the dry season, they are crystallized and fill the existed pores. The drying and watering cycles appear with the changes of air humidity, resulting in the deliquescence/recrystallization of minerals in stone buildings. The crystallization expansion effect will enlarge the volume and produce a crystallization pressure[56], inducing the exfoliation of surface rock structure. Besides, another fact that can not be ignored is the clay swelling phenomenon, which has been reported in many literatures[57-59]. Figure 13 exihibites the clay contents of the five stone sampes, which occupy $4.45 \%-10.29 \%$ of all the minerals. Although the clay content is minor, the water induced swelling of clay will also cause a considerable softening for carbonate rocks[60]. This lowering of the mechanical properties certainly plays a role in the fracturing of the wetted stone surface occurring during the spalling process[61].

Figure 14 shows us the temperature change of a year in Chengde city. The minimum monthly mean temperature ranges from $-14.69^{\circ} \mathrm{C}$ to $19.63^{\circ} \mathrm{C}$, while the maximum monthly mean temperature varies from $-1.28{ }^{\circ} \mathrm{C}$ to $30.52{ }^{\circ} \mathrm{C}$. Besides, the differences of the minimum and maximum mean temperature for a month fall in the range of $10.89-14.57^{\circ} \mathrm{C}$. The notable temperature variation will induce the freezethaw weathering. Which will be more serious when stone buildings are beared with water. The infiltrated water in pores freezes and expands the volume of stone, herein a local tensile stress is induced among the mineral grains of rock, and these will cause partial damage to the rock. With the increase of the number of freeze-thaw cycles, the rock pore becomes bigger and bigger, and the cohesive reaction among mineral grains gradually declines[62], causing the stripping of the stone building heritages. 
In view of the above discussions, it can be seen that water is the crime culprit to cause the degrading of stone buildings. Instead of current defective protective measures (e.g., covering the plastic film onto the stone cultural relics), the fluorinated acrylate copolymer emulsion coating may be an effective method for the conservation of stone building heritages in Putuo Zongcheng Temple. This fluorinated copolymer possesses preferable ability to prevent water from penetrating in the internal structure of a stone. After being coated, the hydrophobicity of stone buildings is improved enormously. And then the dissolution effect, salt crystallization, water absorption swelling and freeze-thaw weathering are avoided or weaken. Moreover, this fluorinated copolymer is capable of againsting the ultraviolet radiation, the favorable ageing-resistance will guarantee a long-term protection for the stone building heritages.

\section{Conclusion}

In this work, a fluorinated acrylate copolymer emulsion was successfully prepared by using the copolymer polymerization process. The FTIR spectra confirms that the adopted monomers has been involved in during the polymerization process. The SEM images reveal the surface characteristics of the fluorinated copolymer. Comparing to the porous structure of stone building heritages, the prepared copolymer is obviously more dense, compact and smooth. The mass loss rate of prepared copolymer increases rapidly and then tends to be stable when irradiated by ultraviolet light. And the mass attenuation is related to the content of HFMA, it has been approved that the fluoropolymer with $16.65 \%$ HFMA content possesses the optimal ageing resistance. Additionally, the contact angle test also exhibits that the the fluoropolymer film with 16.65\% HFMA content has the superb hydrophobicity. After being coated, the contact angles of the stone samples are enormously improved, which leads to an exhaustive wettability alteration for stone building. The following spontaneous imbibition test also ensured this effectiveness. Specially, for the sample treated by the fluoropolymer, the maximum water absorption capacity is lesser and the imbibition equilibrium time is shorter. Considering the influence of water on rock weathering, coating stone building by this fluorinated copolymer emulsion is an potential method to avoid its degrading, because it depresses the infiltration of water and then avoids or weakens the dissolution effect, salt crystallization, water absorption swelling and freeze-thaw weathering.

\section{Declarations}

\section{Funding}

This work was sponsored by the National Natural Science Foundation of China. (Grant No. 11902208).

\section{Availability of data and material:}

The datasets used or analysed during the current study are available from the corresponding author on reasonable request.

\section{Competing interests:}

The authors have declared that no competing interests exist. 


\section{Authors' contributions}

Jiangfang Chang performed the experiment and wrote the manuscript;

Qinghe Niu contributed to the conception of the study;

Wei Wang contributed significantly to analysis and manuscript preparation.

\section{References}

1. Chelazzi D, Poggi G, Jaidar Y, Toccafondi N, Giorgi R, Baglioni P: Hydroxide nanoparticles for cultural heritage: Consolidation and protection of wall paintings and carbonate materials. J. Colloid Interf. Sci. 2013;392:42-49.

2. Zoghlami K, Martín-Martín JD, Gómez-Gras D, Navarro A, Parcerisa D, Rosell JR: The building stone of the Roman city of Dougga (Tunisia): Provenance, petrophysical characterisation and durability. Cr. Geosci. 2017;349:402-411.

3. La Russa MF, Barone G, Belfiore CM, Mazzoleni P, Pezzino A: Application of protective products to "Noto" calcarenite (south-eastern Sicily): a case study for the conservation of stone materials. Environ. Earth Sci. 2011;62:1263-1272.

4. Zhu B, Yu J, Qin X, Rioual P, Zhang Y, Liu Z, Mu Y, Li H, Ren X, Xiong H: Identification of rock weathering and environmental control in arid catchments (northern Xinjiang) of Central Asia. J. Asian Earth Sci. 2013;66:277-294.

5. Al-Omari A, Brunetaud X, Beck K, Al-Mukhtar M: Effect of thermal stress, condensation and freezingthawing action on the degradation of stones on the Castle of Chambord, France. Environ. Earth Sci. 2014;71:3977-3989.

6. Wu Y, Zhang J, Wang L, Wang Y: A rock-weathering bacterium isolated from rock surface and its role in ecological restoration on exposed carbonate rocks. Ecol. Eng. 2017;101:162-169.

7. Gulotta D, Bertoldi M, Bortolotto S, Fermo P, Piazzalunga A, Toniolo L: The Angera stone: a challenging conservation issue in the polluted environment of Milan (Italy). Environ. Earth Sci. 2013;69:1085-1094.

8. Khallaf MK, El-Midany AA, El-Mofty SE: Influence of acrylic coatings on the interfacial, physical, and mechanical properties of stone-based monuments. Prog. Org. Coat. 2011;72:592-598.

9. Zhang H, Liu Q, Liu T, Zhang B: The preservation damage of hydrophobic polymer coating materials in conservation of stone relics. Prog. Org. Coat. 2013;76:1127-1134.

10. Dong R, Liu L: Preparation and properties of acrylic resin coating modified by functional graphene oxide. Appl. Surf. Sci. 2016;368:378-387.

11. Buj O, Gisbert J: Influence of pore morphology on the durability of sedimentary building stones from Aragon (Spain) subjected to standard salt decay tests. Environ. Earth Sci. 2010;61:1327-1336. 
12. Charola AE: Water-Repellent Treatments for Building Stones: A Practical Overview. Apt Bulletin 1995;26:10-17.

13. Melo MJ, Bracci S, Camaiti M, Chiantore O, Piacenti F: Photodegradation of acrylic resins used in the conservation of stone. Polym. Degrad. Stabil. 1999;66:23-30.

14. Pintus V, Wei S, Schreiner M: Accelerated UV ageing studies of acrylic, alkyd, and polyvinyl acetate paints: Influence of inorganic pigments. Microchem. J. 2016;124:949-961.

15. Haas KH, Amberg-Schwab S, Rose K, Schottner G: Functionalized coatings based on inorganicorganic polymers (ORMOCER ${ }^{\circledR} ; \mathrm{s}$ ) and their combination with vapor deposited inorganic thin films. Surf. Coat. Tech. 1999;111:72-79.

16. Sadat Shojai M, Ershad Langroudi A: Polymeric coatings for protection of historic monuments: Opportunities and challenges. J. Appl. Polym. Sci. 2010;112:2535-2551.

17. Chiantore 0 , Lazzari M: Photo-oxidative stability of paraloid acrylic protective polymers. Polymer 2001;42:17-27.

18. Periolatto M, Ferrero F: Cotton and polyester surface modification by methacrylic silane and fluorinated alkoxysilane via sol-gel and UV-curing coupled process. Surf. Coat. Tech. 2015;271:165173.

19. Yang X, Zhu L, Zhang Y, Chen Y, Bao B, Xu J, Zhou W: Surface properties and self-cleaning ability of the fluorinated acrylate coatings modified with dodecafluoroheptyl methacrylate through two adding ways. Appl. Surf. Sci. 2014;295:44-49.

20. He L, Liang J, Zhao X, Li W, Luo H: Preparation and comparative evaluation of well-defined fluorinated acrylic copolymer latex and solution for ancient stone protection. Prog. Org. Coat. 2010;69:352-358.

21. Saïdi S, Guittarda F, Géribaldi S: Synthesis and characterization of copolymers based on styrene and partially fluorinated acrylates. Eur. Polym. J. 2006;42:702-710.

22. Coulson SR, Woodward IS, Badyal JPS, Brewer SA, Willis C: Plasmachemical Functionalization of Solid Surfaces with Low Surface Energy Perfluorocarbon Chains. Langmuir 2000;16:6287-6293.

23. Ciardelli F, Aglietto M, Montagnini Di Mirabello L, Passaglia E, Giancristoforo S, Castelvetro V, Ruggeri G: New fluorinated acrylic polymers for improving weatherability of building stone materials. Prog. Org. Coat. 1997;32:43-50.

24. Toniolo L, Poli T, Castelvetro V, Manariti A, Chiantore O, Lazzari M: Tailoring new fluorinated acrylic copolymers as protective coatings for marble. J. Cult. Herit. 2002;3:309-316.

25. Tsakalof A, Manoudis P, Karapanagiotis I, Chryssoulakis I, Panayiotou C: Assessment of synthetic polymeric coatings for the protection and preservation of stone monuments. J. Cult. Herit. 2007;8:6972.

26. Bhargava S, Kubota M, Lewis RD, Advani SG, Prasad AK, Deitzel JM: Ultraviolet, water, and thermal aging studies of a waterborne polyurethane elastomer-based high reflectivity coating. Prog. Org. Coat. 2015;79:75-82. 
27. Cai G, Zhang D, Jiang D, Dong Z: Degradation of fluorinated polyurethane coating under UVA and salt spray. Part \: Molecular structures and depth profile. Prog. Org. Coat. 2018;124:25-32.

28. Chen L, Shi H, Wu H, Xiang J: Preparation and characterization of a novel fluorinated acrylate resin. J. Fluorine Chem. 2010;131:731-737.

29. Zhang Y, Qi Y, Zhang Z, Sun G: Synthesis of fluorinated acrylate polymer and preparation and properties of antifouling coating. Journal of Coatings Technology and Research 2015;12:215-223.

30. Niu Q, Pan J, Cao L, Ji Z, Wang H, Wang K, Wang Z: The evolution and formation mechanisms of closed pores in coal. Fuel 2017;200:555-563.

31. Bongiovanni R, Pollicino N, Gozzelino G, Malucelli G, Priola A, Ameduri B: Surface properties of networks containing fluorinated acrylic monomers. Polym. Advan. Technol. 2015;7:403-408.

32. Dettinger U, Egelhaaf H, Brabec CJ, Latteyer F, Peisert H, Chassé T: FTIR Study of the Impact of $\mathrm{PC}[60] \mathrm{BM}$ on the Photodegradation of the Low Band Gap Polymer PCPDTBT under O2 Environment. Chem. Mater. 2015;27:2299-2308.

33. Andrady AL, Hamid SH, Hu X, Torikai A: Effects of increased solar ultraviolet radiation on materials. Journal of Photochemistry and Photobiology B: Biology 1998;46:96-103.

34. Montagna LS, Catto AL, Camargo Forte MMD, Chiellini E, Corti A, Morelli A, Campomanes Santana RM: Comparative assessment of degradation in aqueous medium of polypropylene films doped with transition metal free (experimental) and transition metal containing (commercial) pro-oxidant/prodegradant additives after exposure to controlled UV radiation. Polym. Degrad. Stabil. 2015;120:186192.

35. Ha J, Park IJ, Lee S: Hydrophobicity and Sliding Behavior of Liquid Droplets on the Fluorinated Latex Films. Macromolecules 2005;38:736-744.

36. Wei X, Zhang G, Zhou L, Li J: Synthesis and characterization of hydrophobic amino-based polyphosphazene microspheres with different morphologies via two strategies. Appl. Surf. Sci. 2017;419:744-752.

37. Zeng $X$, Ma Y, Wang Y: Enhancing the low surface energy properties of polymer films with a dangling shell of fluorinated block-copolymer. Appl. Surf. Sci. 2015;338:190-196.

38. Feng C, Kong Y, Jiang G, Yang J, Pu C, Zhang Y: Wettability modification of rock cores by fluorinated copolymer emulsion for the enhancement of gas and oil recovery. Appl. Surf. Sci. 2012;258:70757081.

39. Çelik MY, Kaçmaz AU: The investigation of static and dynamic capillary by water absorption in porous building stones under normal and salty water conditions. Environ. Earth Sci. 2016;75:307.

40. Pan J, Niu Q, Wang K, Shi X, Li M: The closed pores of tectonically deformed coal studied by smallangle X-ray scattering and liquid nitrogen adsorption. Micropor. Mesopor. Mat. 2016;224:245-252.

41. Ling S, Wu X, Zhao S, Liao X: Evolution of porosity and clay mineralogy associated with chemical weathering of black shale: A case study of Lower Cambrian black shale in Chongqing, China. J. Geochem. Explor. 2018;188:326-339. 
42. Momeni AA, Khanlari GR, Heidari M, Sepahi AA, Bazvand E: New engineering geological weathering classifications for granitoid rocks. Eng. Geol. 2015;185:43-51.

43. Cueto N, Benavente D, Martínez-Martínez J, García-Del-Cura MA: Rock fabric, pore geometry and mineralogy effects on water transport in fractured dolostones. Eng. Geol. 2009;107:1-15.

44. Özvan A, Dinçer 0, Akın M, Oyan V, Tapan M: Experimental studies on ignimbrite and the effect of lichens and capillarity on the deterioration of Seljuk Gravestones. Eng. Geol. 2015;185:81-95.

45. Licchelli M, Malagodi M, Weththimuni M, Zanchi C: Nanoparticles for conservation of bio-calcarenite stone. Applied Physics A 2014;114:673-683.

46. Jiang Y, Li L, Liu J, Wang R, Wang H, Tian Q, Li X: Hydrophobic films of acrylic emulsion by incorporation of fluorine-based copolymer prepared through the RAFT emulsion copolymerization. J. Fluorine Chem. 2016;183:82-91.

47. Li M, Li Y, Xue F, Jing X: Water-based acrylate copolymer/silica hybrids for facile preparation of robust and durable superhydrophobic coatings. Appl. Surf. Sci. 2018;447:489-499.

48. Liu X, Wang Z, Zhao C, Bu W, Zhang Y, Na H: Synthesis, characterization and evaluation of a fluorinated resin monomer with low water sorption. J. Mech. Behav. Biomed. 2018;77:446-454.

49. Mousavi MA, Hassanajili S, Rahimpour MR: Synthesis of fluorinated nano-silica and its application in wettability alteration near-wellbore region in gas condensate reservoirs. Appl. Surf. Sci. 2013;273:205-214.

50. Handy LL: Determination of effective capillary pressures for porous media from imbibition data. Petroleum Transactions, AIME 1960;219:75-80.

51. Wang S, Hao J: Air quality management in China: Issues, challenges, and options. J. Environ. Sci.China 2012;24:2-13.

52. Eyssautier-Chuine S, Marin B, Thomachot-Schneider C, Fronteau G, Schneider A, Gibeaux S, Vazquez $P$ : Simulation of acid rain weathering effect on natural and artificial carbonate stones. Environ. Earth Sci. 2016;75:748.

53. Gibeaux S, Vázquez P, De Kock T, Cnudde V, Thomachot-Schneider C: Weathering assessment under X-ray tomography of building stones exposed to acid atmospheres at current pollution rate. Constr. Build. Mater. 2018;168:187-198.

54. Guney $Y$, Sari D, Cetin M, Tuncan M: Impact of cyclic wetting-drying on swelling behavior of limestabilized soil. Build. Environ. 2007;42:681-688.

55. Zhang BY, Zhang JH, Sun GL: Deformation and shear strength of rockfill materials composed of soft siltstones subjected to stress, cyclical drying/wetting and temperature variations. Eng. Geol. 2015;190:87-97.

56. Ghobadi MH, Babazadeh R: An investigation on the effect of accelerated weathering on strength and durability of Tertiary sandstones (Qazvin province, Iran). Environ. Earth Sci. 2015;73:4237-4250.

57. Amorim CLG, Lopes RT, Barroso RC, Queiroz JC, Alves DB, Perez CA, Schelin HR: Effect of clay-water interactions on clay swelling by X-ray diffraction. Nuclear Instruments and Methods in Physics 
Research Section A: Accelerators, Spectrometers, Detectors and Associated Equipment 2007;580:768-770.

58. Hassine MA, Beck K, Brunetaud X, Al-Mukhtar M: Strain measurements during capillary water infiltration in porous limestones. Constr. Build. Mater. 2018;175:439-447.

59. Jimenez Gonzalez I, Scherer GW: Effect of swelling inhibitors on the swelling and stress relaxation of clay bearing stones. Environmental Geology 2004;46:364-377.

60. Cherblanc F, Berthonneau J, Bromblet P, Huon V: Influence of Water Content on the Mechanical Behaviour of Limestone: Role of the Clay Minerals Content. Rock Mech. Rock Eng. 2016;49:20332042.

61. Berthonneau J, Bromblet P, Cherblanc F, Ferrage E, Vallet J, Grauby O: The spalling decay of building bioclastic limestones of Provence (South East of France): From clay minerals swelling to hydric dilation. J. Cult. Herit. 2016;17:53-60.

62. Tan X, Chen W, Yang J, Cao J: Laboratory investigations on the mechanical properties degradation of granite under freeze-thaw cycles. Cold Reg. Sci. Technol. 2011;68:130-138.

\section{Figures}

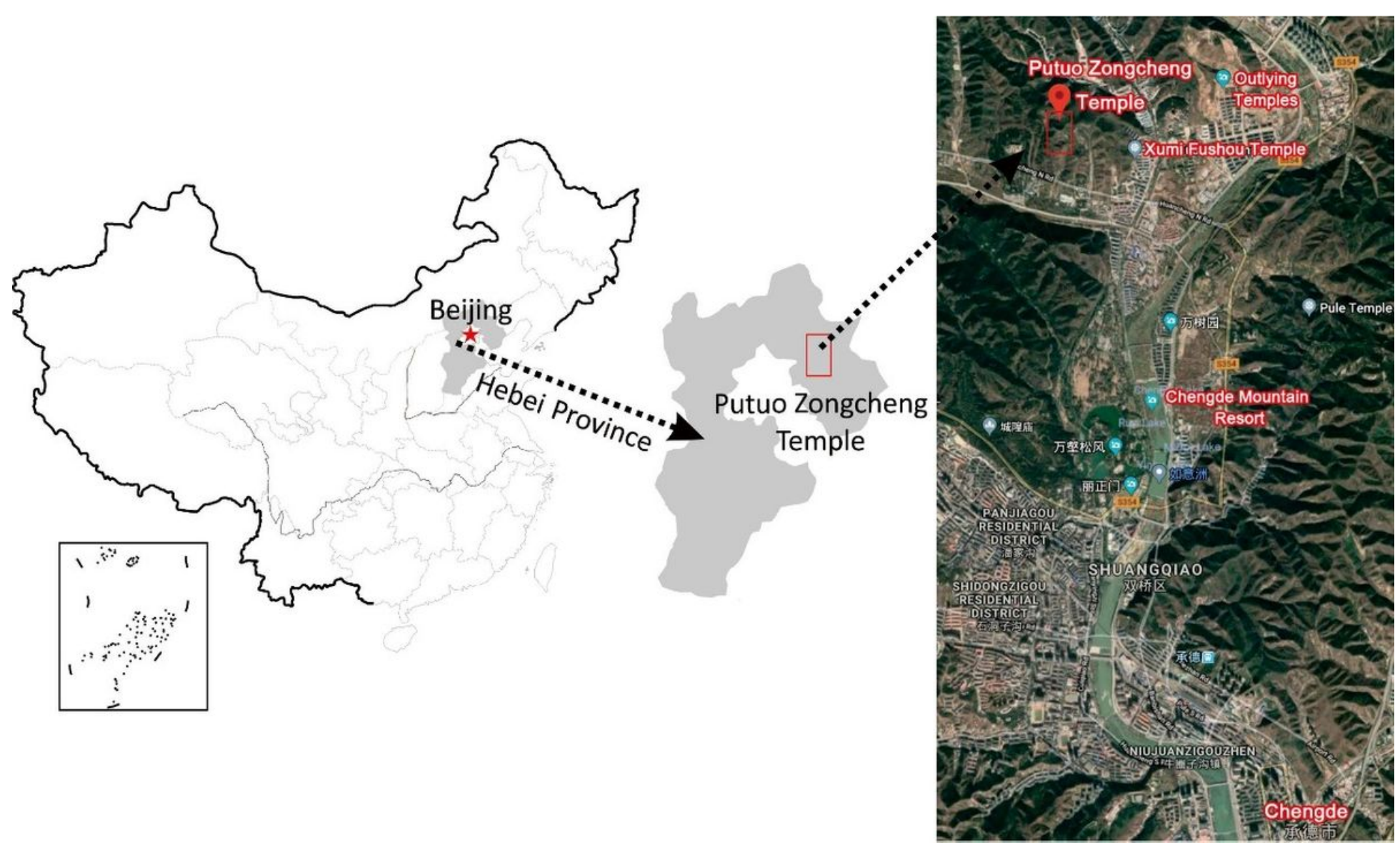

Figure 1 
Location of Putuo Zongcheng Temple. Note: The designations employed and the presentation of the material on this map do not imply the expression of any opinion whatsoever on the part of Research Square concerning the legal status of any country, territory, city or area or of its authorities, or concerning the delimitation of its frontiers or boundaries. This map has been provided by the authors.

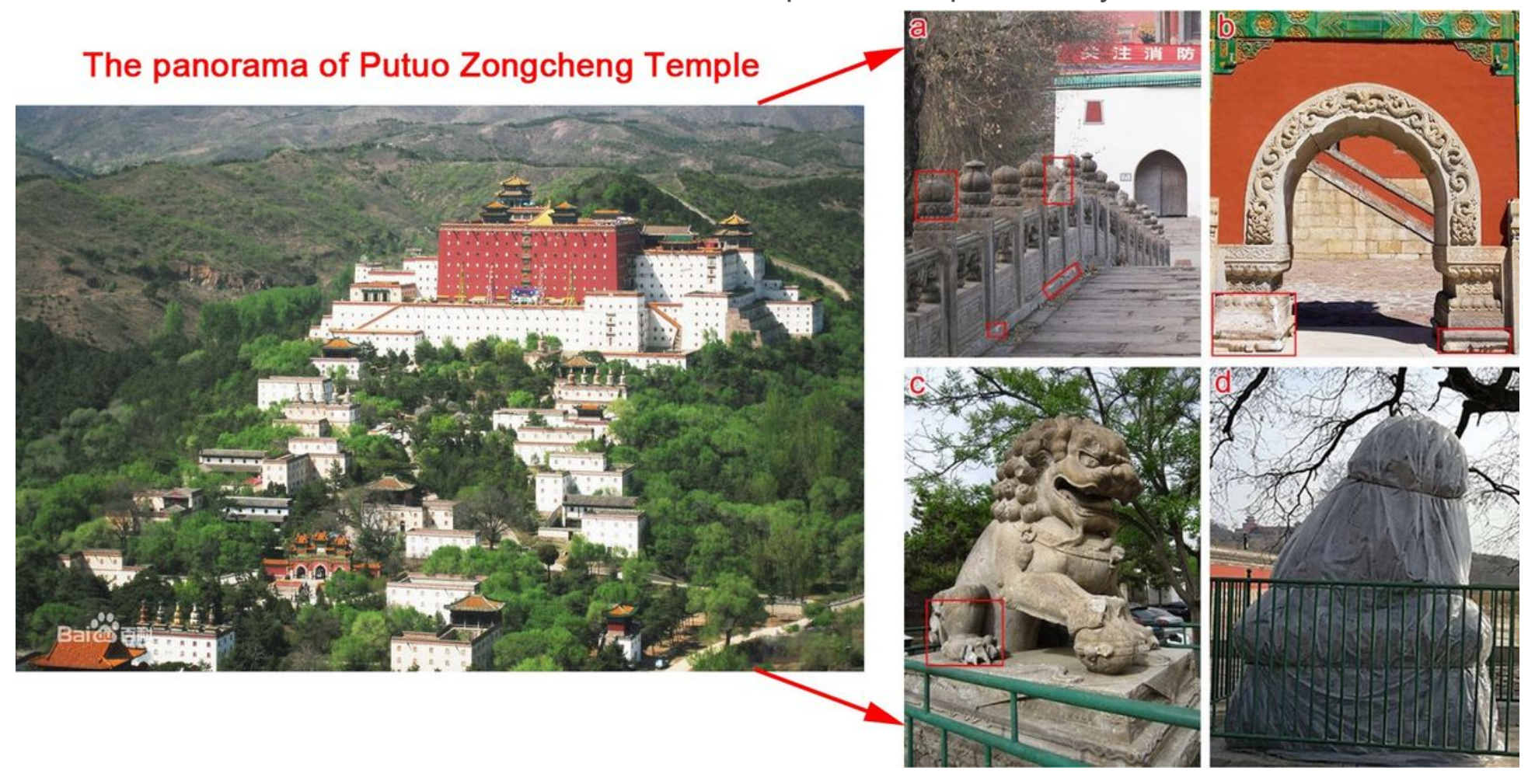

\section{Figure 2}

Presentations of the weathered stone bridge, stone wall and stone lion. 


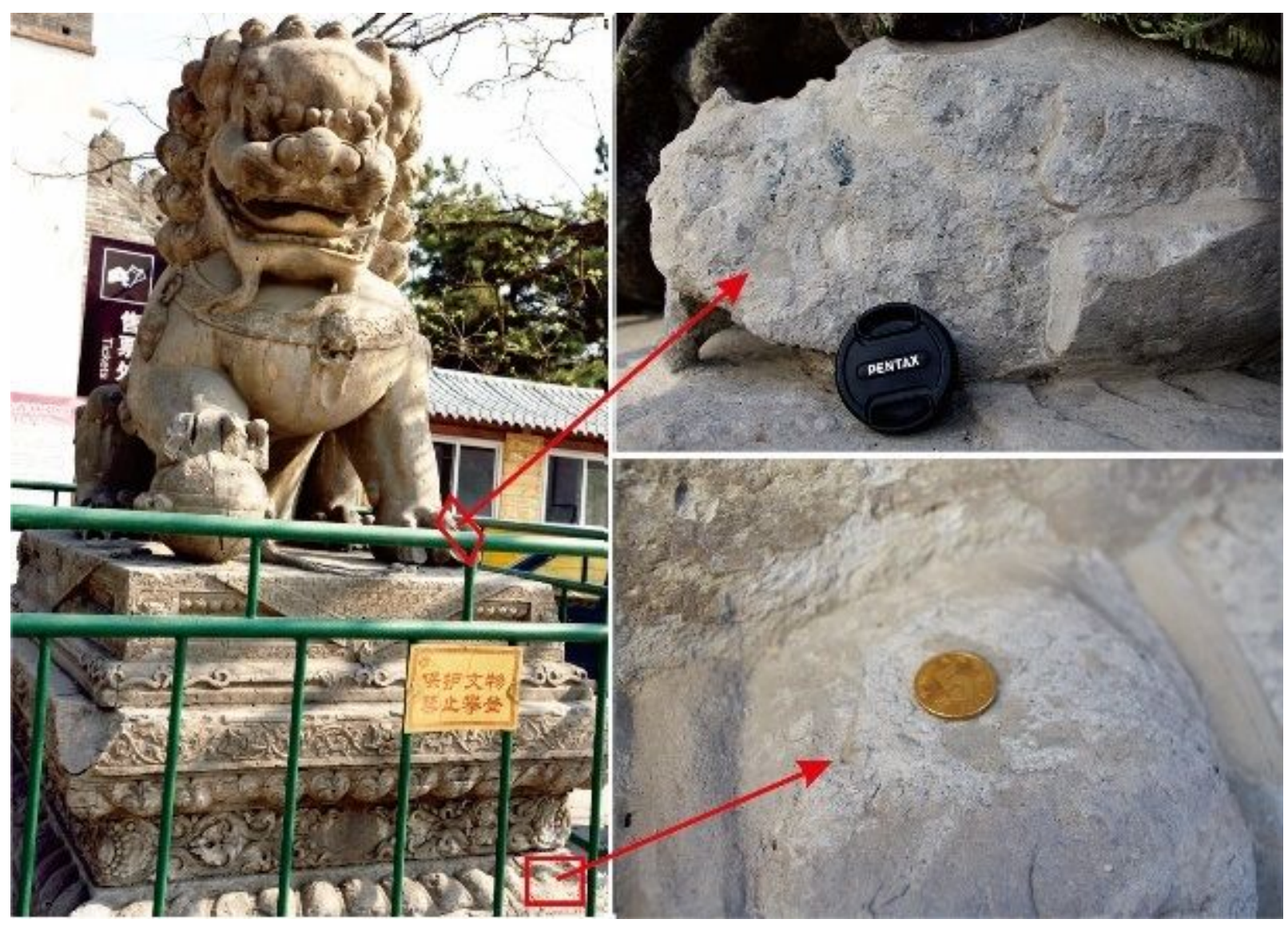

Figure 3

A detail display of the weathered foots and pedestal of stone lion.
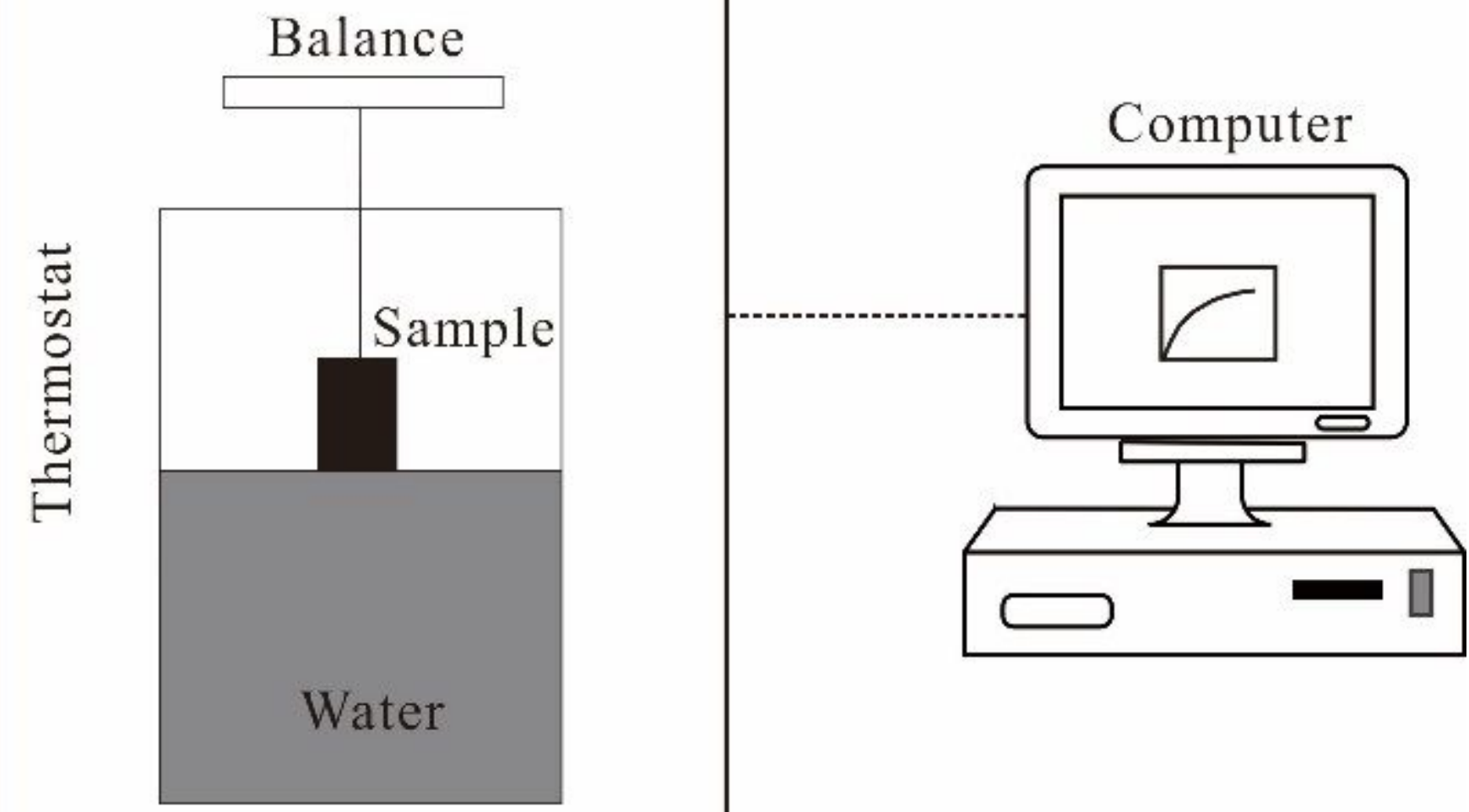
Figure 4

Sketch of the apparatus for spontaneous imbibition test.

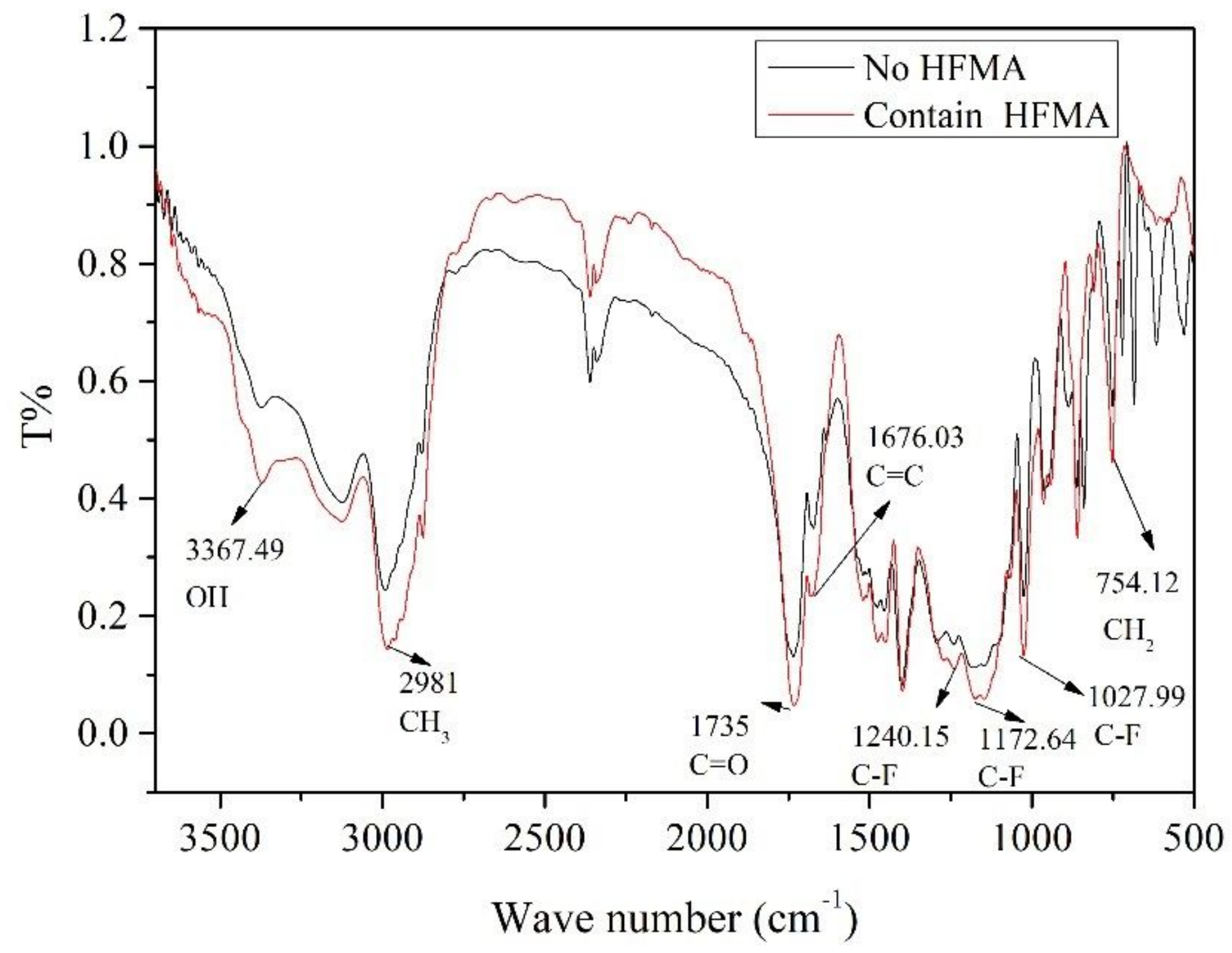

Figure 5

FTIR spectra of the prepared copolymer. 


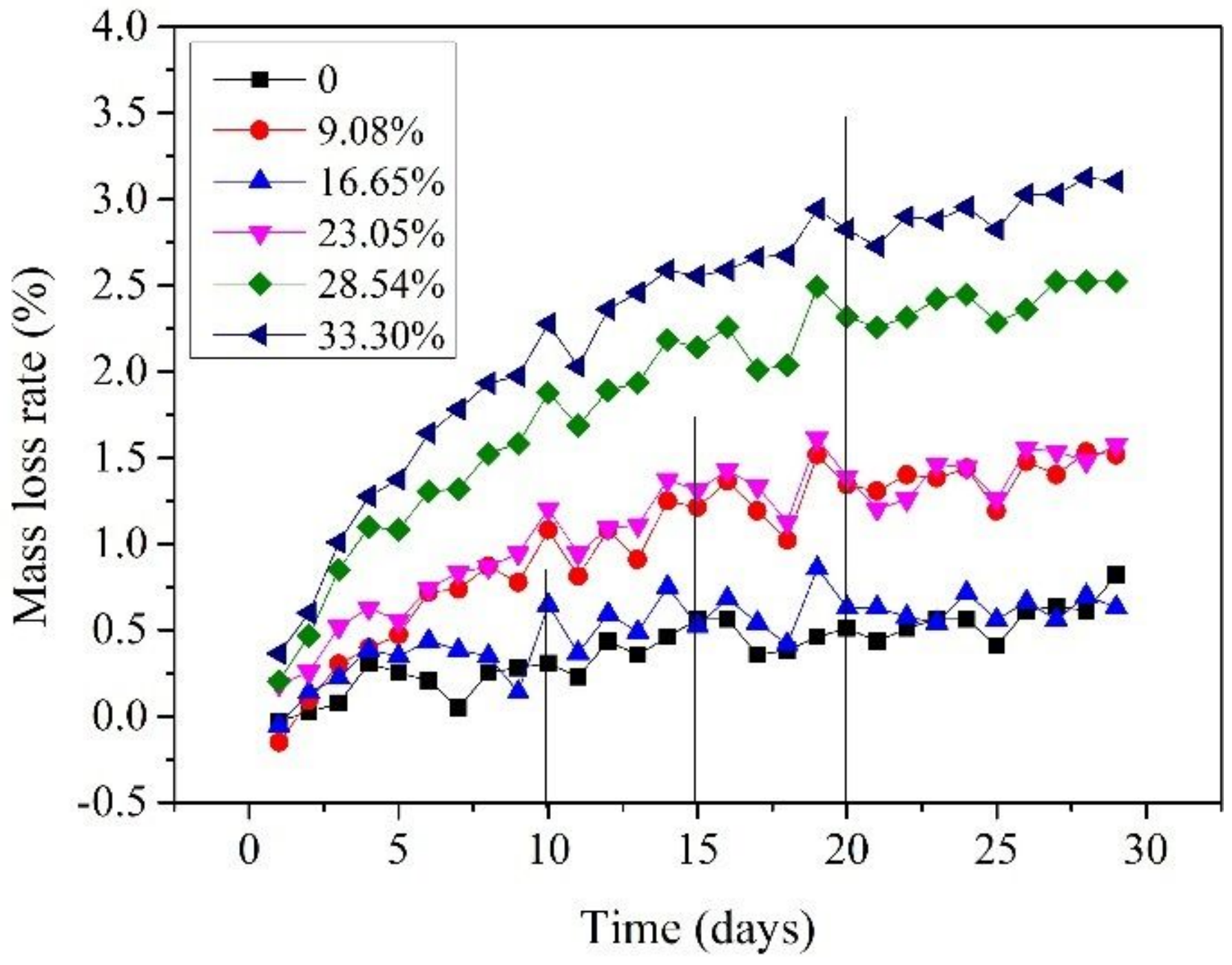

Figure 6

The mass loss rate of the prepared copolymer with different HFMA contents versus the ultraviolet radiation time. 


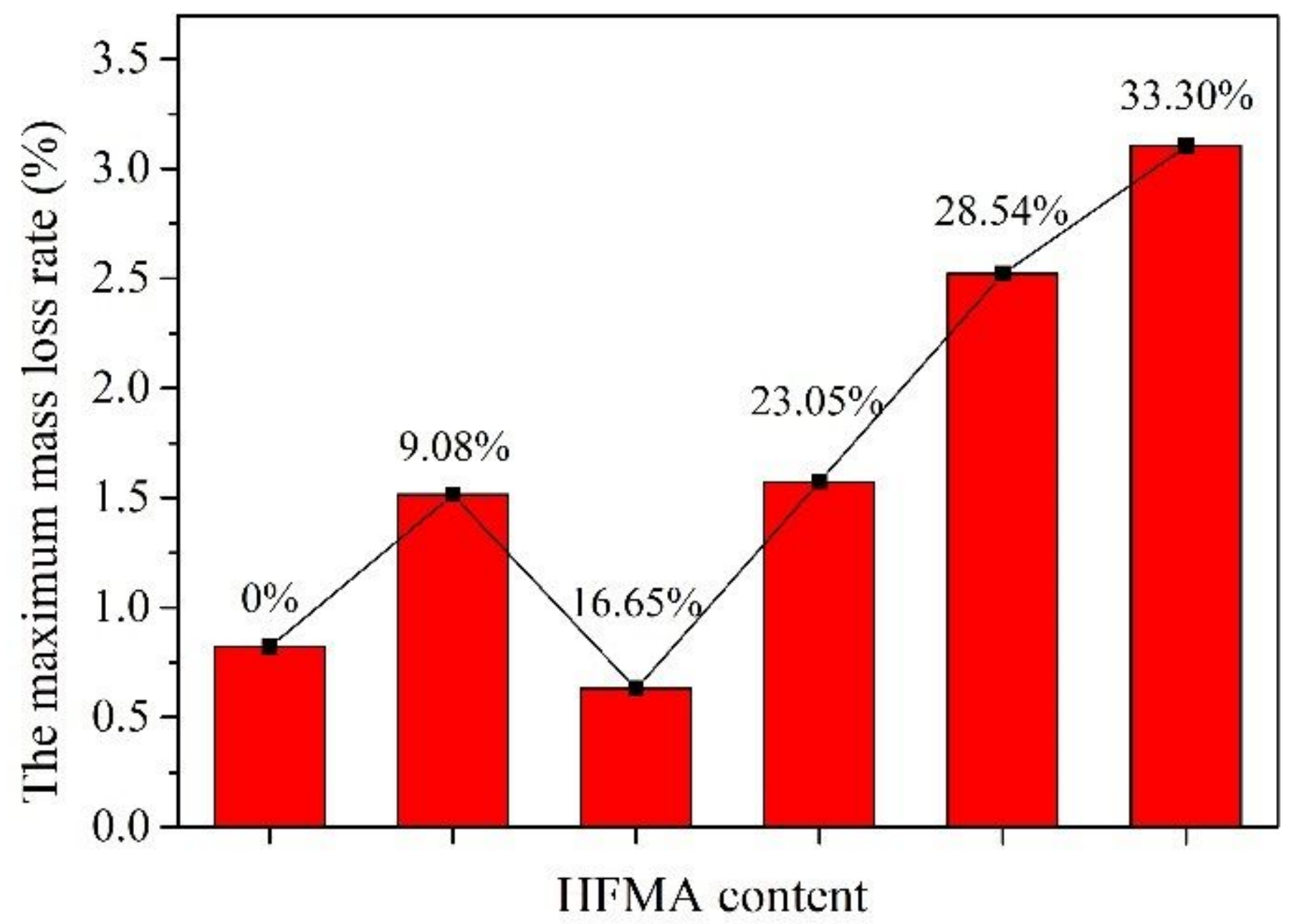

Figure 7

The maximum mass loss rate of copolymers with different HFMA contents. 


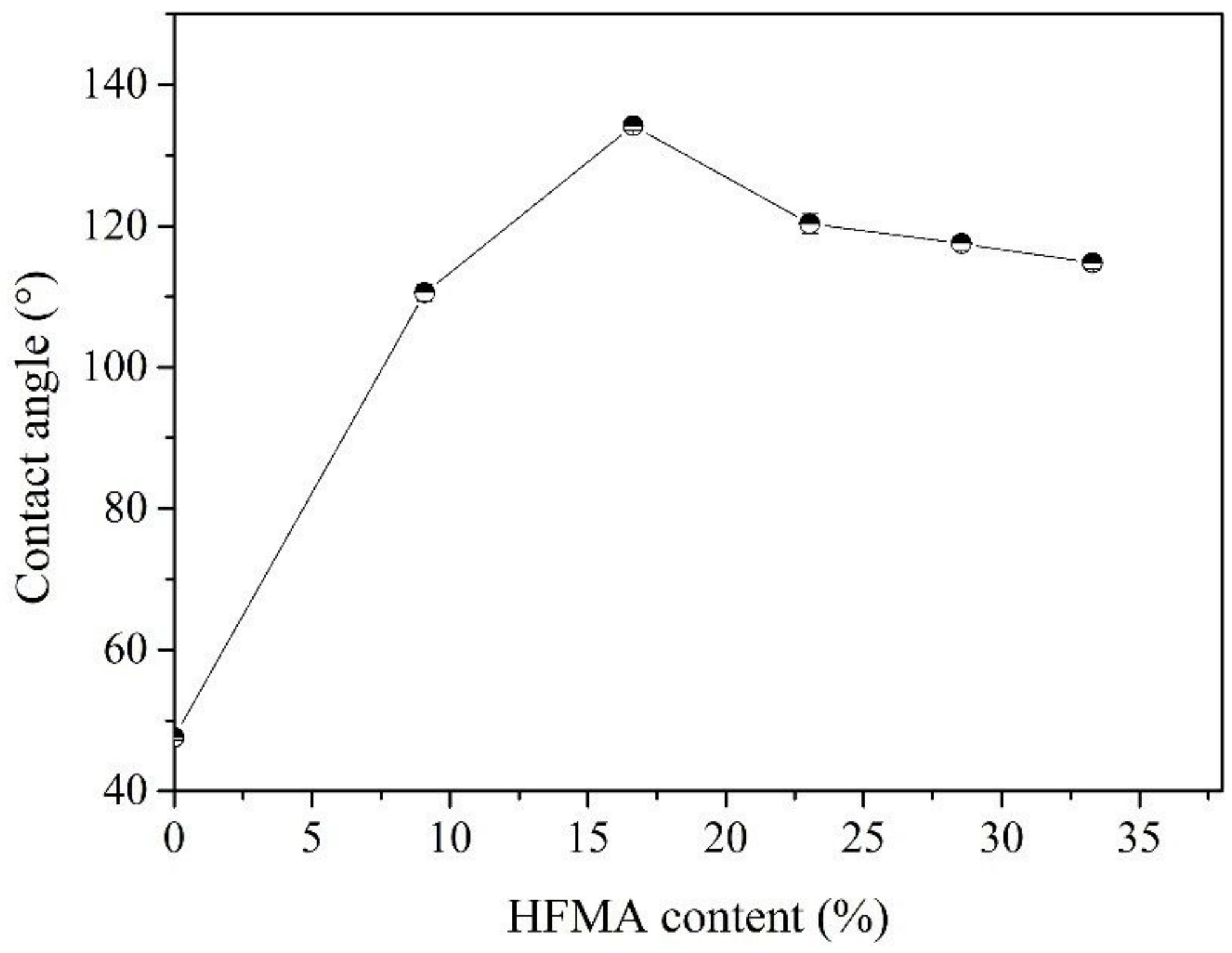

Figure 8

Contact angle of copolymers with different HFMA contents. 

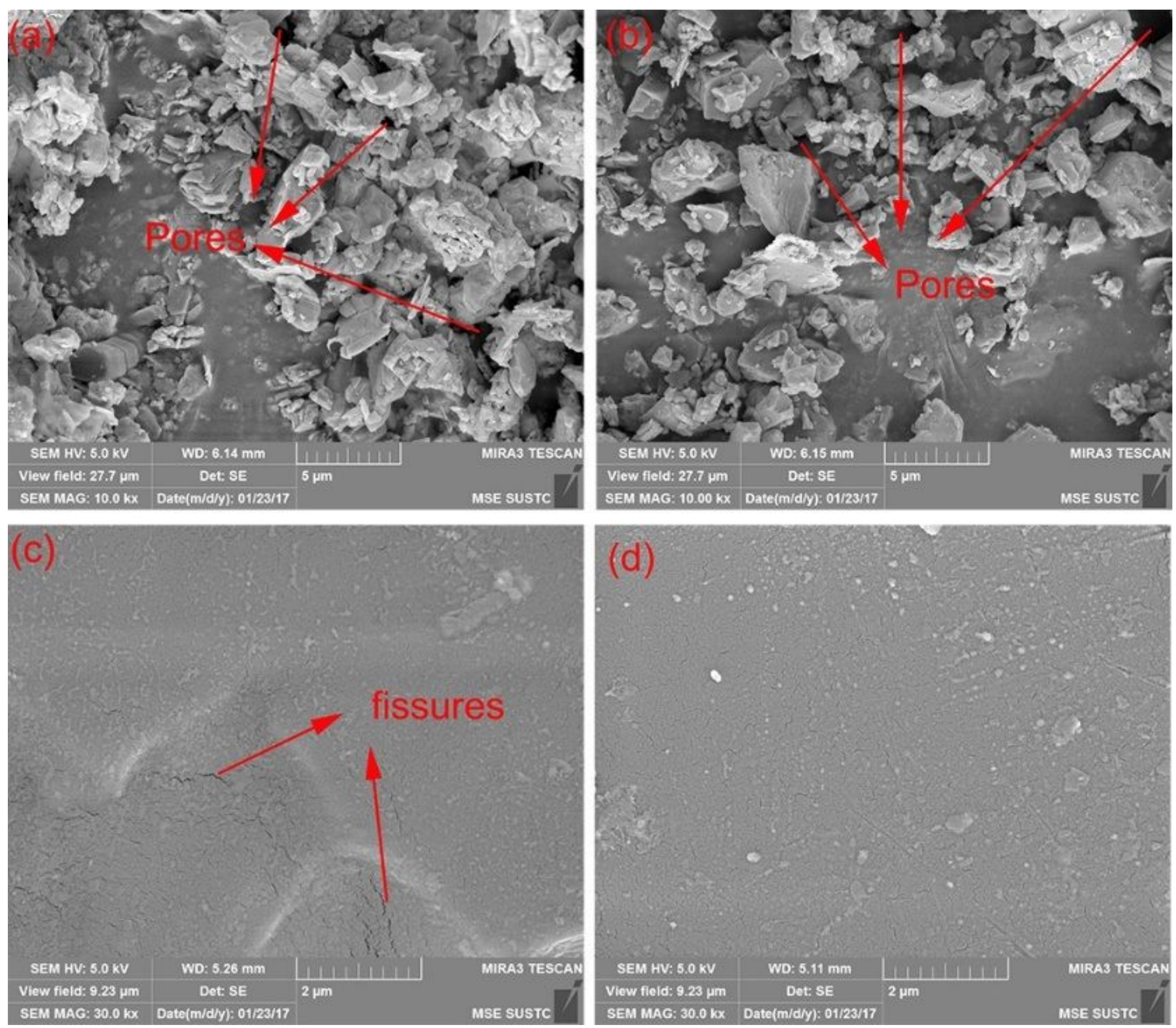

\section{Figure 9}

The SEM images of weathered stone samples and fluorinated copolymers. (a) and (b) are the surface topography of stone samples, which come from the stone lion and the footing of wall; (c) and (d) are the surface topography of prepared copolymer synthesised without and with HFMA. 


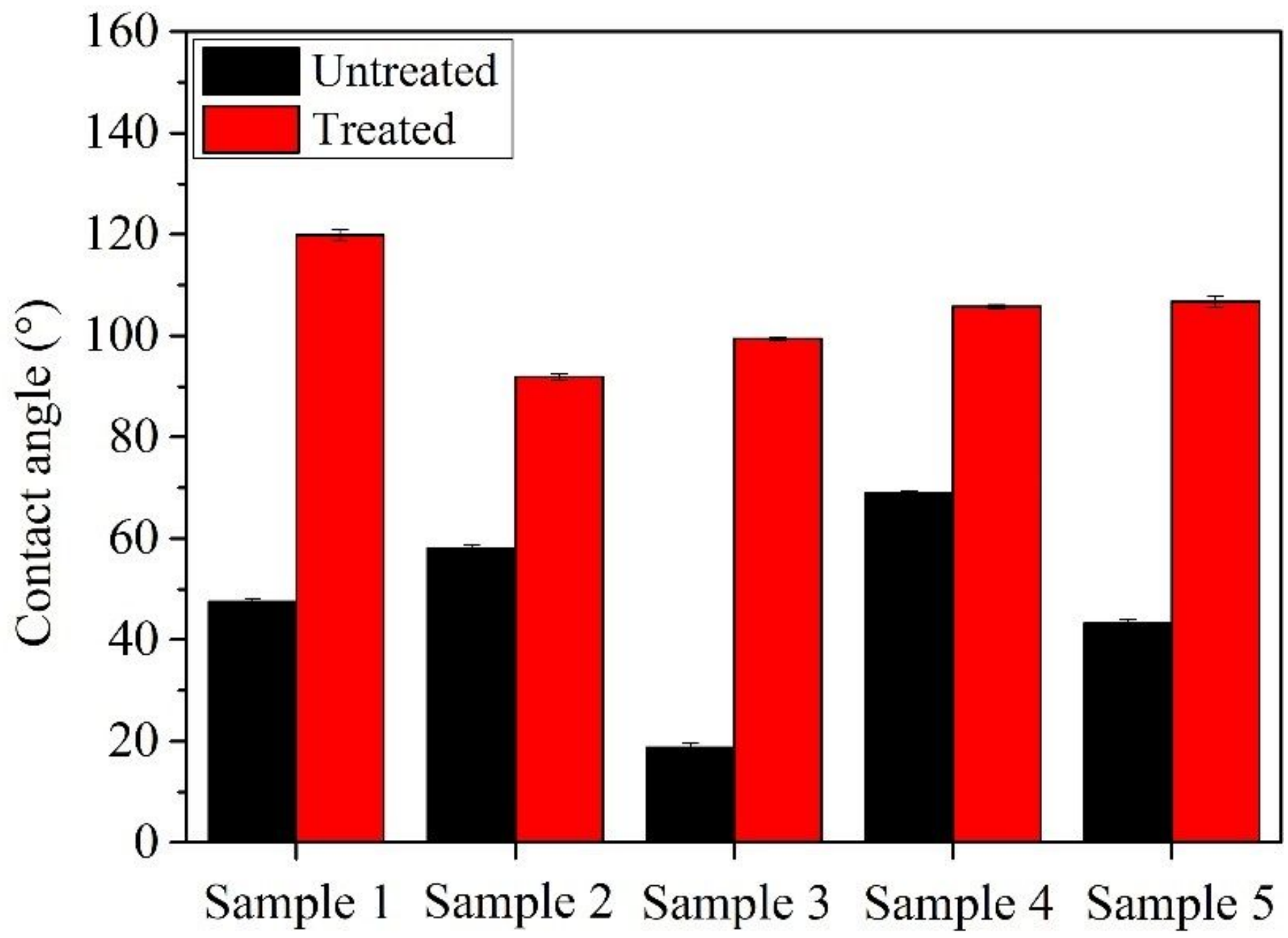

Figure 10

The contact angles of the five stone samples before and after the fluorinated acrylate copolymer emulsion coating. 


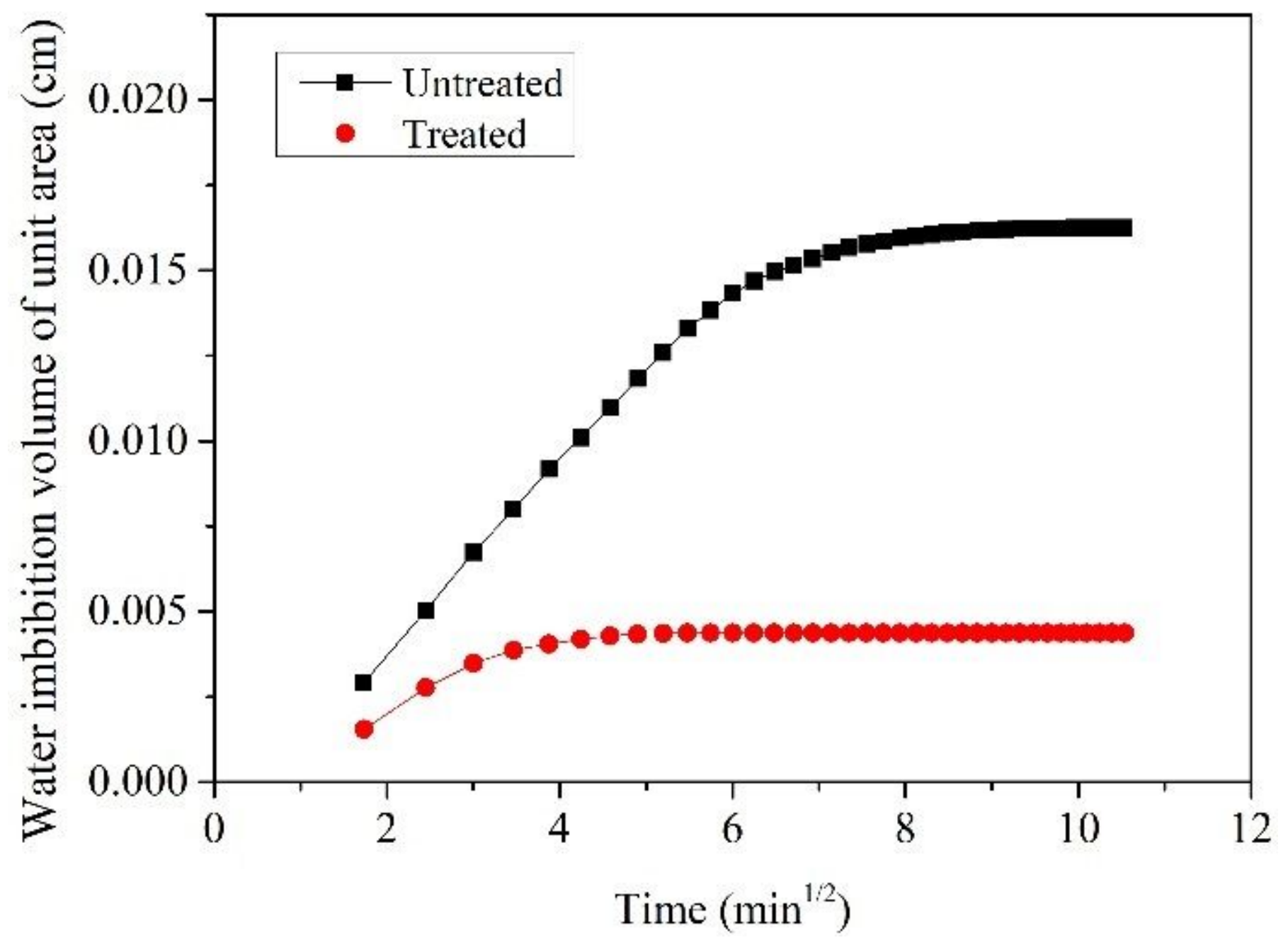

Figure 11

The changes of water imbibition volume with imbibition time. 


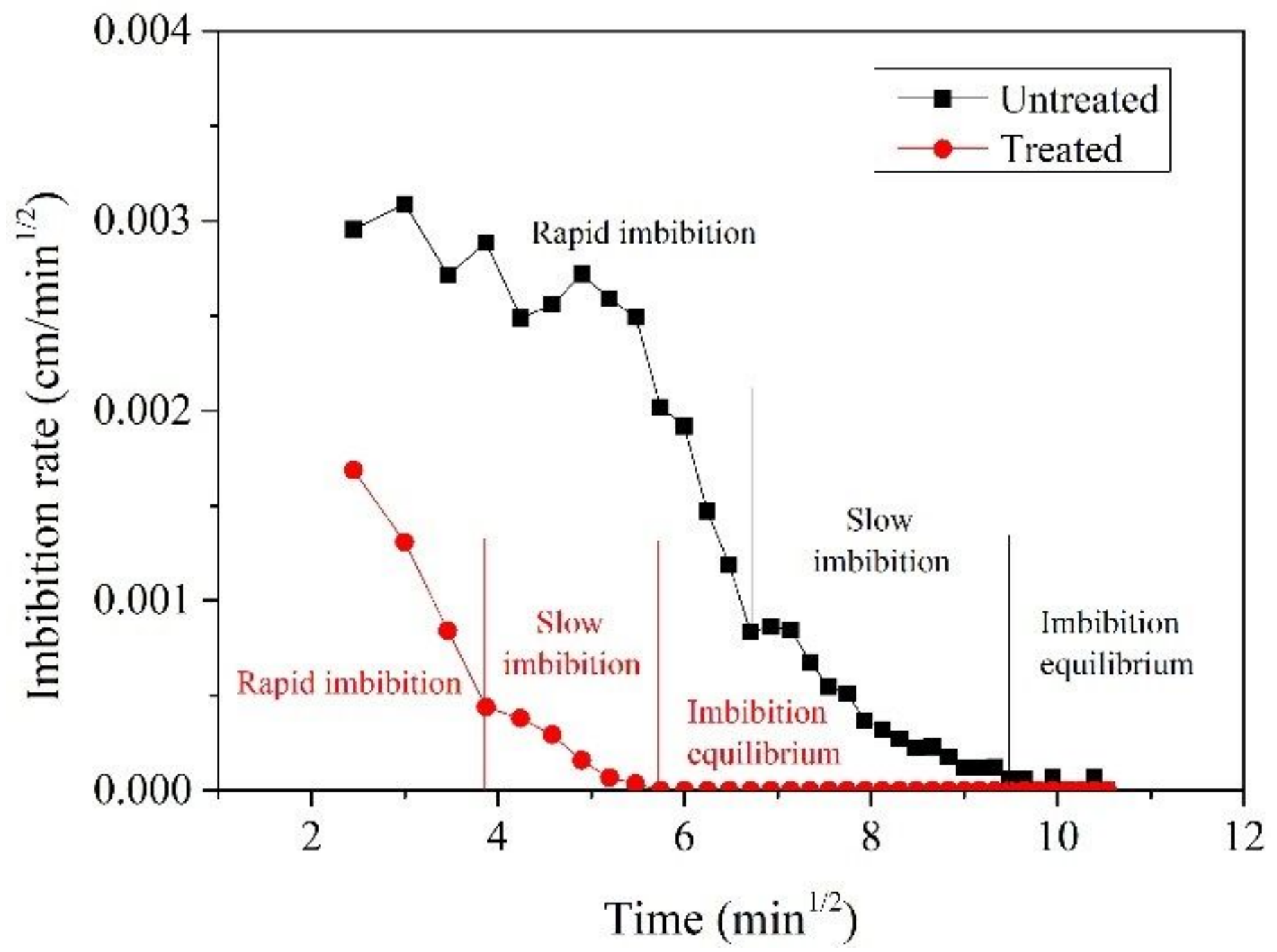

Figure 12

The relationship of imbibition rate and imbibition time. 


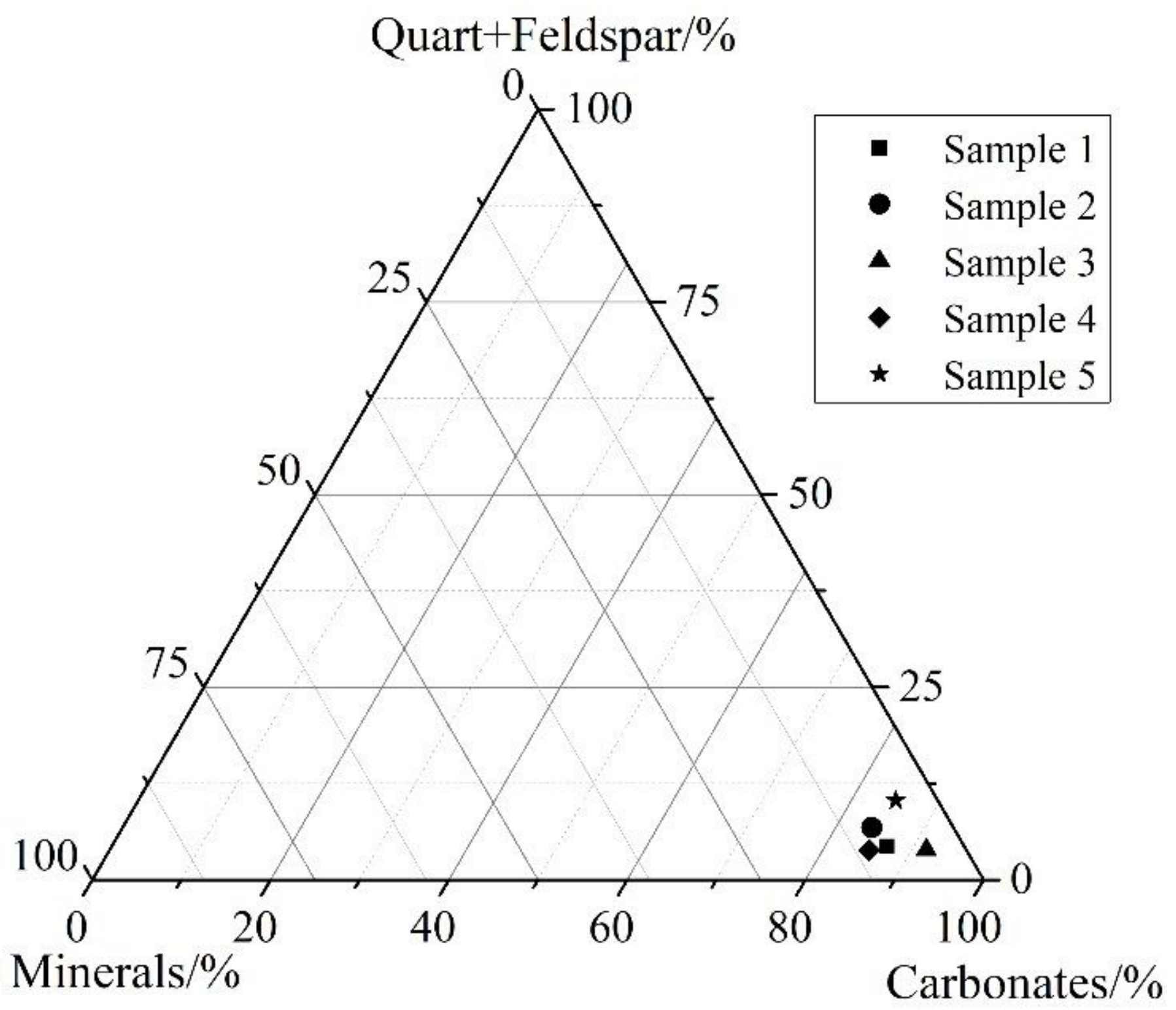

Figure 13

Ternary diagram displaying the contents of carbonates, quartz+feldspar, and clay minerals of the five selected stone samples. 


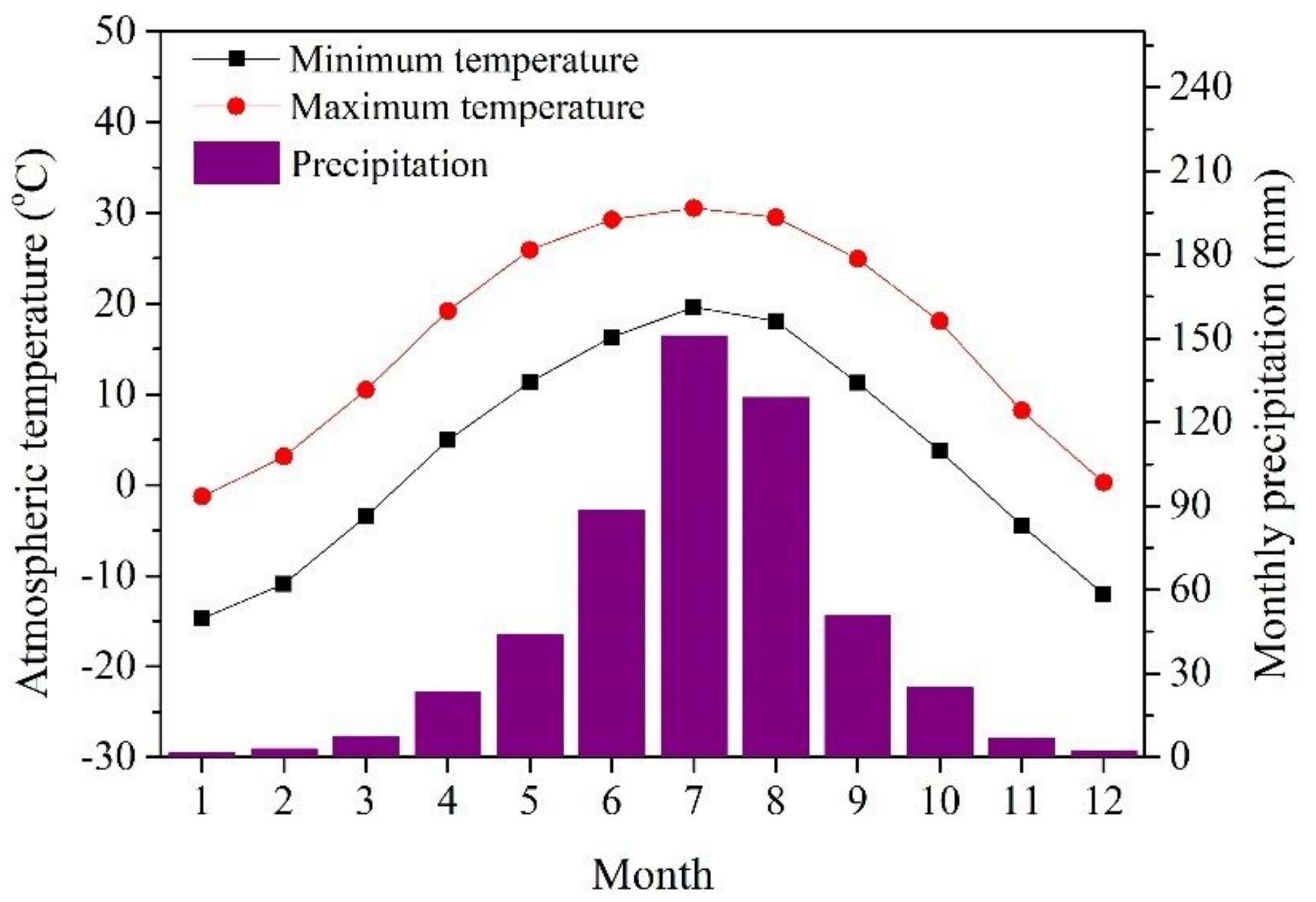

Figure 14

The monthly mean minimum atmospheric temperature, maximum atmospheric temperature and precipitation of 2017 in Chengde city (Data from the China Meteorological Administration). 